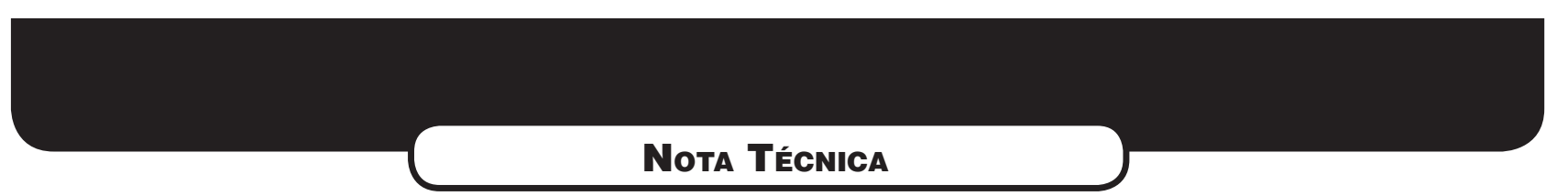

\title{
REMOÇÃo de SULFATO de ÁGUAS RESIDUÁRIAS INDUSTRIAIS EM REATOR ANAERÓBIO DE LEITO FIXO OPERADO EM BATELADAS SEQUENCIAIS
}

\author{
SULFATE REMOVAL FROM INDUSTRIAL WASTEWATERS IN FIXED FILM ANAEROBIC \\ SEQUENTIAL BATCH REACTOR
}

ARNALDO SARTI
Engenheiro Químico (UFSCar). Doutor em Engenharia Civil. Área Hidráulica e Saneamento (EESC/USP). Pós-Doutor
do Departamento de Hidráulica e Saneamento (EESC/USP)

\section{ARIovaldo José DA SILVA}

Tecnólogo em Saneamento (CESET/Unicamp). Doutor em Engenharia Civil. Área Hidráulica e Saneamento (EESC/USP). Professor CESET /Unicamp (Limeira/SP) e Faculdade CBTA (Rio Claro/SP)

\author{
ROBERTO SARTI CÔRTES \\ Graduando Engenharia Civil (EESC/USP). Iniciação Científica do Departamento de Hidráulica e \\ Saneamento (EESC/USP)
}

\section{EUGENIO FORESTI}

Engenheiro Civil (EESC/USP). Doutor em Engenharia Civil (EESC/USP) - Departamento de Hidráulica e Saneamento. Professor Titular do Departamento de Hidráulica e Saneamento (EESC/USP)

\section{Recebido:14/03/07 Aceito: 06/11/07}

\section{RESUMO}

Avaliou-se o potencial de uso reator anaeróbio operado em bateladas seqüenciais com biomassa imobilizada (ASBBR), em escala piloto, no tratamento de água residuária industrial contendo elevadas concentraçôes de sulfato. O ASBBR, com volume total de $1.2 \mathrm{~m}^{3}$, foi preenchido com carvão mineral como meio suporte para imobilização da biomassa (leito fixo). Foram aplicadas cargas de 0,$15 ; 0,30 ; 0,65 ; 1,30 \mathrm{e}$ $1,90 \mathrm{~kg} \mathrm{SO}_{4}^{-2} /$ ciclo (ou batelada) com duração de $48 \mathrm{~h}$, correspondendo, respectivamente, às concentraçōes de sulfato no afluente de 0,$25 ; 0,50 ; 1,0 ; 2,0$ e $3,0 \mathrm{gSO}_{4}^{-2} \cdot t^{-1}$. Utilizou-se etanol como doador de elétrons para a redução do sulfato. $\mathrm{O}$ reator foi operado à temperatura ambiente $\left(29 \pm 8^{\circ} \mathrm{C}\right)$, tendo sido obtidas eficiências médias na redução de sulfato entre 88 e $92 \%$ em 92 ciclos (275 dias). Os resultados obtidos permitem concluir que o uso de reatores ASBBR constitui-se em alternativa eficiente para a remoção de sulfatos de águas residuárias com características semelhantes às utilizadas neste trabalho.

PALAVRAS-CHAVE: Sulfato, tratamento anaeróbio, reator anaeróbio operado em bateladas seqüenciais com biomassa imobilizada, carvão mineral, etanol.

\section{INTRODUÇÃO}

O Departamento Nacional de Produção Mineral, DNPM, relata que, em 2005, o Brasil importou aproximadamente 2,0 milhóes de toneladas

\begin{abstract}
The potential use of an anaerobic sequencing batch biofilm reactor $(A S B B R)$ in pilot-scale for the treatment of a sulfate-rich industrial wastewater was evaluated. The pilot $1.2 \mathrm{~m}^{3} \mathrm{ASBBR}$ reactor was filled with mineral coal for biomass immobilization (fixed film). The sulfate loading rates applied were 0.15; 0.30; $0.65 ; 1.30$ and $1.90 \mathrm{~kg} \mathrm{SO}_{4}^{-2} / \mathrm{cycle}$ (or batch). Each cycle lasted $48 \mathrm{~h}$. The influent concentrations were, respectively, 0.25; 0.50; 1.0; 2.0 and $3.0 \mathrm{gSO}_{4}^{-2} . \mathrm{l}^{-1}$. Ethanol was used as electron donor for sulfate reduction. The reactor operated at ambient temperature $\left(29 \pm 8^{\circ} \mathrm{C}\right)$, and the mean efficiencies of sulfate removal were in the range 88 to $92 \%$ in the 92 run cycles. The total operating period comprised 275 days. Based on the results obtained in this research, it could be concluded that the ASBBR can be an efficient alternative for the removal of sulfate from other industrial wastewaters with similar characteristics.
\end{abstract}

KEYWORDS: Sulfate, anaerobic treatment, anaerobic sequencing batch biofilm reactor, mineral coal, ethanol. de compostos de enxofre, entre bens primários e compostos industrializados (ácido sulfúrico, enxofre sublimado, pirita, etc.), correspondente ao dispêndio de US\$108,6 milhões e exportou 6,0 mil toneladas de enxofre como bens primários (por exemplo, a pirita) e compostos industrializados (por exemplo, ácido sulfúrico). O consumo de enxofre no país decorre, principalmente, de sua aplicação na agricultura (53\%) nas indústrias químicas (47\%) para produ- 
ção de ácido sulfúrico, sendo que 70 a $80 \%$ do produto destinam-se à produção de fertilizantes. O enxofre é utilizado, ainda, em outros importantes setores industriais, tais como para a fabricação de pigmentos inorgânicos, papel celulose, borracha, bissulfeto de carbono, explosivos, açúcar e cosméticos. Portanto, grande parte do enxofre importado é lançada em nossos rios na forma de sulfato, contribuindo para a degradação dos cursos d'água brasileiros.

As descargas indiscriminadas diretas ou indiretas de águas residuárias contendo sulfato, em corpos receptores, podem prejudicar a qualidade das águas e também interferir no ciclo natural do enxofre. Nas zonas anaeróbias, o íon sulfato é reduzido a sulfeto de hidrogênio, aumentando a demanda química de oxigênio. Dessa forma, o lançamento indiscriminado de sulfato num corpo de água compromete o processo natural de autodepuração.

Considerando os problemas que o sulfato pode causar se lançado indiscriminadamente no ambiente, os órgãos de controle ambiental têm exigido que as fontes emissoras reduzam as concentraçôes desse ânion nas águas residuárias. No Estado de São Paulo, a Lei no 997 de 31 de maio de 1976, regulamentada pelo Decreto Estadual 8468 de 1976, no Artigo 19a, estabelece a concentração máxima de $1,0 \mathrm{gSO}_{4}{ }^{2-} \cdot 1^{-1} \mathrm{em}$ efluentes líquidos lançados direta ou indiretamente nos corpos receptores, impondo obrigatoriedade de tratamento às fontes emissoras cujas concentrações de sulfato no efluente ultrapassem o valor determinado.

No Brasil, os processos físicos e químicos utilizados, para remoção de sulfato incluem desde alternativas de menor custo, como precipitação com sais de cálcio, a processos mais caros como osmose reversa, eletrodiálise e nanofiltração. Processos de precipitação química resultam em grande quantidade de resíduos sólidos devido à quantidade de reagente a ser empregada. Esses resíduos devem ser adequadamente dispostos, incorporando custos para classificação, manuseio e destinação (Silva et al, 2002).

No processo de osmose reversa, a concentração de sulfato limita a vida útil da membrana devido à precipitação deste ânion, além de gerar rejeito na forma de salmoura (Silva et al, 2002).
Os demais processos têm o custo proporcional à concentração de sulfato, de forma que altas concentrações chegam a inviabilizá-los. Neste caso, para o tratamento de águas residuárias com elevadas concentrações de sulfato, a remoção biológica apresenta-se como alternativa aos processos físico-químicos. Dependendo da concentração de sulfato na água residuária e das restrições legais para emissão do ânion, pode ser interessante a união de processos físicos e químicos aos processos biotecnológicos.

$\mathrm{Na}$ última década, várias alternativas biotecnológica têm sido desenvolvidas para a remoção de ânions de enxofre oxidados $\left(\mathrm{SO}_{3}{ }^{2-}, \mathrm{HSO}_{3}\right.$, $\mathrm{S}_{2} \mathrm{O}_{3}^{2-}, \mathrm{SO}_{4}^{2-}$, etc) de efluentes líquidos industriais. Primeiro, os óxidos de enxofre são transformados em sulfeto $\left[\mathrm{H}_{2} \mathrm{~S}(\mathrm{~g})+\mathrm{H}_{2} \mathrm{~S}(\mathrm{aq})+\mathrm{HS}^{-}\right]$em ambiente anaeróbio. Os ânions de enxofre reduzidos são subseqüentemente re-oxidados para enxofre elementar $\left(S^{0}\right)$, o qual pode ser recuperado (Lens et al,1998).

Em anos recentes, os reatores para remoção de sulfato têm sido projetados com objetivo de maximizar a redução anaeróbia de sulfato. $\mathrm{Na}$ presença de sulfato, os microrganismos redutores de sulfato (MRS) proliferam nos reatores, onde competem com microrganismos metanogênicos e microrganismos homoacetogênicos por substratos comuns tais como hidrogênio, acetato, etanol e metanol. Têm sido reportados estudos voltados ao projeto de unidades para o tratamento biológico de sulfato, como os filtros anaeróbios (Chian \& De Walle, 1983), reatores em batelada (Herrera et al, 1991), reatores de leito fixo (Du Preez \& Maree, 1994; Stucki et al, 1993), reatores de leito fluidizado (Nagpal et al, 2000; Federovich et al, 2000), reatores "gas-lift" (Van Houten et al, 1995; Kaufman et al, 1996), reatores de leito granular expandido (De Smul et al, 1997; Weijma et al, 2003) e reatores de chicanas (Grobicki \& Stuckey, 1992).

Atualmente, os principais reatores biológicos utilizados comercialmente e em grande escala são o FSBR (Falling Sludge Bed Reactor) and UASB (Upflow Anaerobic Sludge Bed) que correspondem ao Biosure Process (Africa do Sul) e ao Pacques Process (Holanda), respectivamente (HulshoffPol et al, 2001).

Estes processos são de grande interesse na remoção de compostos oxidados de enxofre para as águas residuárias que não contêm doador de elétrons ou fonte de carbono (ou contêm em quantidade insuficiente) para a completa redução do sulfato. Para essas águas residuárias, é requerida a adição de um doador de elétrons apropriado. A seleção do doador de elétrons depende do custo do composto adicionado por unidade de sulfato reduzido e da poluição residual decorrente da degradação parcial do composto adicionado, a qual deve ser baixa ou facilmente removível. Com base neste último critério, compostos orgânicos simples (etanol, metanol) ou gás de síntese (mistura de $\mathrm{H}_{2}, \mathrm{CO}$ e $\mathrm{CO}_{2}$ ) são preferíveis em relação a substratos orgânicos mais complexos (Van Houten, 1996).

Este trabalho apresenta e discute os resultados obtidos por um reator anaeróbio operado em bateladas seqüenciais com biomassa imobilizada (ASBBR-Anaerobic Sequencing Batch Biofilm Reactor) em carvão mineral e recirculação de líquido durante a fase reacional, reator este concebido para promover a redução do sulfato presente em água residuária industrial. O etanol comercial (vendido em postos de abastecimento) foi escolhido como o doador de elétrons, pela grande disponibilidade e facilidade de aquisição no mercado brasileiro e pelo baixo custo.

\section{MATERIAL E MÉTODOS}

\section{Água residuária}

A água residuária rica em sulfato era proveniente de indústria química que tem, como principal atividade, a fabricação de óleo para acabamento de couros animais, processo este baseado na sulfonação de óleos vegetais (arroz, soja e milho). A reação completa de sulfonação ocorre na presença de ácido sulfúrico $\left(\mathrm{H}_{2} \mathrm{SO}_{4}\right)$ e amônia (líquido) em reator operado em batelada e sob temperatura controlada. No final do processo de sulfonação, ocorre a lavagem do óleo produzido com água, cujo objetivo principal é a eliminação dos ácidos livres. A composição da água residuária de lavagem com alta concentração de sulfato é apresentada na Tabela 1.

\section{Reator ASBBR (projeto e operação)}

O ASBBR (escala-piloto) foi confeccionado em fibra de vidro, com 
volume total de $1.2 \mathrm{~m}^{3}$, tendo sido preenchido com leito fixo composto de peças irregulares de carvão mineral ( 40 a $80 \mathrm{~mm}$ de diâmetro). A massa de carvão mineral para composição do leito foi de $500 \mathrm{~kg}$ para o volume de reator de $1.0 \mathrm{~m}^{3}$, resultando no volume de líquido de $0.5 \mathrm{~m}^{3}$ (porosidade leito- $50 \%$ ).

Ovolume destinado ao "head-space" no ASBBR foi de $0.2 \mathrm{~m}^{3}$, sendo de $0,1 \mathrm{~m}^{3}$ o volume ocupado pelo líquido acima do leito de carvão em virtude da necessidade de se manter a tubulação de recirculação sempre cheia. Portanto, o volume disponível para tratamento por ciclo ou batelada era de $0.6 \mathrm{~m}^{3}$ $\left(0.5+0.1 \mathrm{~m}^{3}\right)$. A tubulação de saída do biogás foi imersa em recipiente (100 litros) contendo solução alcalina $(\mathrm{NaOH})$.

A seleção do material suporte para o ASBBR (escala piloto) baseou-se no trabalho de Silva et al. (2006), substituindo-se o carvão vegetal por carvão mineral, que é mais denso que a água e, portanto, não exige dispositivo especial para sua retenção no reator. Adicionalmente, o carvão mineral é extraído em larga escala no sul do Brasil (SC) e pode ser adquirido a baixo custo $(\mathrm{R} \$ 1,75 \mathrm{ou}$ USD \$ $0.81 / \mathrm{kg}$ carvão mineral).

No ASBBR, a agitação foi provida pela recirculação ascendente do líquido por meio de bomba centrífuga Jacuzzimodelo 5JL15, cuja canalização de recalque estava conectada a um tubo perfurado situado na base do leito de carvão ao longo do diâmetro do reator. A mesma bomba de recirculação foi empregada para a alimentação do reator (afluente) proveniente do reservatório de $0.6 \mathrm{~m}^{3}$. Foi adotado o tempo de ciclo de 48 horas, compreendendo as etapas de alimentação (1 h), reação com recirculação de líquido contínua (46 h) e descarte $(1 \mathrm{~h})$. A Figura 1 apresenta o desenho esquemático da instalação experimental utilizada na pesquisa.

$\mathrm{O}$ reator foi instalado no Laboratório de Processos Biológicos (EESC-USP, São Carlos), que dispõe de sistema de captação de esgotos da rede pública. No experimento, o esgoto sanitário (Tabela 2) foi utilizado para diluir a água residuária industrial rica em sulfato (Tabela 1), a fim de permitir a operação do reator na concentração de sulfato desejada.

O ASBBR foi mantido à temperatura ambiente média de $29 \pm 8^{\circ} \mathrm{C}$ ao longo dos 275 dias de operação (92 ciclos). Durante o experimento,

Tabela I - Composição dos principais constituintes da água residuária industrial (20 amostras)

\begin{tabular}{cccc}
\hline Variáveis & Mínimo & Máximo & Média \\
\hline $\mathrm{pH}$ & 2,30 & 3,20 & - \\
$\mathrm{DQO}_{\text {Total }}\left(\mathrm{g} . \mathrm{l}^{-1}\right)$ & 9,20 & 15,40 & $12,70 \pm 4,1$ \\
$\mathrm{DQO}_{\text {Filtrada }}\left(\mathrm{g} . \mathrm{l}^{-1}\right)$ & 9,02 & 10,90 & $10,60 \pm 1,4$ \\
$\mathrm{NH}_{4}^{+}\left(\mathrm{g} . \mathrm{l}^{-1}\right)$ & 1,30 & 1,80 & $1,50 \pm 0,5$ \\
$\mathrm{SO}_{4}^{-2}\left(\mathrm{~g} . \mathrm{l}^{-1}\right)$ & 180 & 284 & $201 \pm 35$ \\
\hline
\end{tabular}

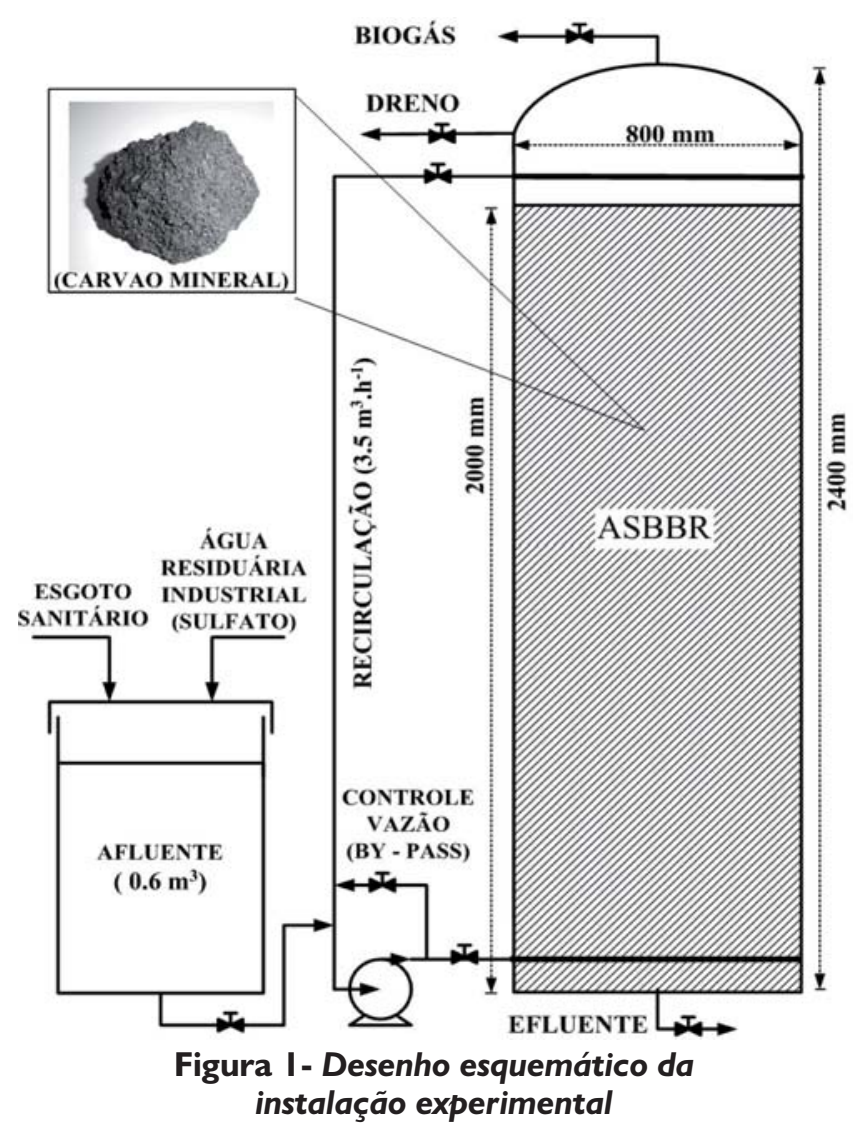

a concentração de sulfato afluente ao reator foi incrementada por meio da diluição em esgoto sanitário, tendo sido aplicadas concentrações de 0,$25 ; 0,50$; 1,$0 ; 2,0$ e $3,0 \mathrm{gSO}_{4}^{-2} \cdot t^{-1}$.

A Tabela 3 apresenta, de forma resumida, as variáveis operacionais aplicadas ao ASBBR nas diferentes etapas experimentais. No reator, foi aplicada inicialmente a carga de sulfato (CS) de $0,15 \mathrm{kgSO}_{4}^{-2} /$ ciclo (Etapa I- $\left.0,25 \mathrm{gSO}^{-2} \cdot \mathrm{l}^{-1}\right)$, sendo esta incrementada até $1,9 \mathrm{kgSO}_{4}^{-2} /$ ciclo (Etapa $\left.\mathrm{V}-3,0 \mathrm{gSO}_{4}^{-2} \cdot l^{-1}\right)$ ao longo do ensaio experimental. Salienta-se que, na Etapa I, apenas o esgoto doméstico foi usado como doador de elétrons (Etapa I). Já na Etapa II $\left(0,30 \mathrm{kgSO}_{4}^{-2} /\right.$ ciclo ou $\left.0,5 \mathrm{gSO}_{4}^{-2} \cdot l^{-1}\right)$ foi adicionado, também, o etanol adquirido de postos de abastecimento de combustíveis, como fonte suplementar de doadores de elétrons para a redução biológica do sulfato. $\mathrm{O}$ volume adicionado foi sendo ajustado progressivamente, em função das eficiências obtidas na redução de sulfato, bem como da relação $\mathrm{DQO} /\left[\mathrm{SO}_{4}{ }_{4}^{2-}\right]$ (Tabela 3). Portanto, não se aplicou estequiometria reacional específica, visando à maximização do processo de conversão do sulfato e redução do consumo de etanol simultaneamente.

Deve ser ressaltado que a relação $\mathrm{DQO} /\left[\mathrm{SO}_{4}{ }^{2-}\right]$ é um dos principais fatores para definir a interação entres microrganismos metanogênicos e os redutores de sulfato. Como existe na literatura especializada discor- 
dância sobre os valores de relação $\mathrm{DQO} /\left[\mathrm{SO}_{4}^{2-}\right]$ a serem aplicados para tratamento biológico de águas residuárias ricas em sulfato por processo anaeróbio, partiu-se da premissa que, na hipótese de esta relação ser igual a 0,67 , há sulfato suficiente para que toda a fonte de matéria orgânica seja consumida via sufetogênese (Lens et al,1998). Para situações em que esses valores são elevados, os processos metanogênicos e sufetogênicos (redução de sulfato) podem ocorrer simultaneamente e, abaixo deste, a sufetogênese poder ser a predominante.

\section{Monitoramento (análises físico-químicas)}

O monitoramento do reator ASBBR foi realizado durante 275 dias (92 ciclos) por meio de análises físico-químicas (afluente e efluente) tais como Demanda Química de Oxigênio (DQO) total e filtrada (membrana 1,2 $\mu \mathrm{m})$, Nitrogênio Amoniacal $\left(\mathrm{NH}_{4}^{+}\right)$, Sólidos Suspensos Totais (SST) e Sólidos Suspensos Voláteis (SSV) e $\mathrm{pH}$ conforme Standard Methods for the Examination of Water and Wastewater (19 ${ }^{\text {th }}$ Edition, 1998). As determinações de Ácidos Voláteis Totais (AVT) como ácido acético $\left(\mathrm{H}_{\mathrm{AC}}\right)$ e alcalinidade a bicarbonato $(A B)$ seguiram metodologia descrita por Dillalo \& Albertson (1961) e modificada por Ripley et al. (1986), respectivamente. O método de azul de metileno (Standard Methods for the Examination of Water and Wastewater: método 4500-D) foi usado para determinação de sulfetos totais dissolvidos (STD). As concentrações de sulfato foram medidas pelo método turbidimétrico, com o uso do reagente $\mathrm{HACH}$ sulfaver.

A quantificação da concentração de biomassa no inóculo foi avaliada pela análise de Sólidos Totais (ST) e Sólidos Totais Voláteis (STV), de acordo com o Standard Methods for the Examination of Water and Wastewater $19^{\text {th }}$ Edition (1995). A medida direta da biomassa no carvão mineral, durante o experimento, ao final de cada Etapa, foi estimada promovendo-se a secagem da amostra em estufa $\left(105{ }^{\circ} \mathrm{C}-24 \mathrm{~h}\right)$ e, em seguida, a calcinação em mufla $\left(540{ }^{\circ} \mathrm{C}-30 \mathrm{~min}\right)$. A diferençade peso da amostra antes e depois o tratamento térmico fornece o peso em massa da biomassa. Esta metodologia para o carvão mineral foi

Tabela 2-Composição dos principais constituintes do esgoto sanitário (50 amostras)

\begin{tabular}{|c|c|c|c|}
\hline Variáveis & Mínimo & Máximo & Média \\
\hline Temperatura $\left({ }^{\circ} \mathrm{C}\right)$ & 15 & 25 & $21 \pm 2$ \\
\hline $\mathrm{pH}$ & 6,6 & 7,7 & - \\
\hline $\mathrm{AB}\left(\mathrm{mgCaCO}_{3}^{-2} \cdot \mathrm{l}^{-1}\right)$ & 84 & 206 & $130 \pm 24$ \\
\hline AVT (mgHac.l $\left.{ }^{-1}\right)$ & 25 & 59 & $45 \pm 13$ \\
\hline DQOTotal (mg..$\left.^{-1}\right)$ & 406 & 860 & $569 \pm 112$ \\
\hline DQOFiltrada (mg. $\left.\mathrm{l}^{-1}\right)$ & 173 & 307 & $243 \pm 33$ \\
\hline NTotal (mg. $\left.1^{-1}\right)$ & 18 & 66 & $41 \pm 5$ \\
\hline $\mathrm{PO}_{4}^{-2}\left(\mathrm{mg} \cdot \mathrm{l}^{-1}\right)$ & 12 & 19 & $14 \pm 2$ \\
\hline $\mathrm{SO}_{4}^{-2}\left(\mathrm{mg} \cdot \mathrm{l}^{-1}\right)$ & 10 & 31 & $24 \pm 8$ \\
\hline SST (mg. $\left.1^{-1}\right)$ & 83 & 269 & $131 \pm 44$ \\
\hline $\operatorname{SSV}\left(\mathrm{mg} . \mathrm{l}^{-1}\right)$ & 68 & 209 & $105 \pm 34$ \\
\hline
\end{tabular}

adaptada de Nagpal et al (2000) com pérolas de vidro.

\section{Inóculo anaeróbio}

O reator ASBBR foi inoculado com $0,2 \mathrm{~m}^{3}$ de lodo anaeróbio $\left(47,2 \mathrm{kgST} . \mathrm{m}^{-3}\right.$ e $\left.33,1 \mathrm{kgSTV} \cdot \mathrm{m}^{-3}\right)$ proveniente de reator UASB $\left(50 \mathrm{~m}^{3}\right)$ instalado na Estação de Tratamento de Esgotos Sanitários do Campus da Universidade de São Paulo (São Carlos-SP). Para completar o volume a ser tratado pelo reator $\left(0,6 \mathrm{~m}^{3}\right)$, adicionou-se esgoto sanitário (rede coletora pública) e a bomba de recirculação foi acionada. A cada batelada ou ciclo, o reator era realimentado totalmente com esgoto sanitário. Esta operação durou 24 dias, ou seja, 12 ciclos de 48 horas. As concentraçóes de ST e STV na partida do ASBBR foram de 15,7 kgST.m ${ }^{-3}$ e $11,1 \mathrm{kgSTV} . \mathrm{m}^{-3}(\mathrm{STV} / \mathrm{ST}=0.7)$.

\section{RESULTADOS E DISCUSSÃO}

As análises de monitoramento do ASBBR foram realizadas semanalmente (2 coletas), sendo que, nos finais de semana, a unidade era alimentada normalmente com efluente industrial diluído para manutenção de operação. Os resultados médios das variáveis obtidas pelo reator ASBBR nos 92 ciclos operacionais para as várias Etapas de operação estão apresentados na Tabela 4.

Conforme estabelece a Legislação vigente no Estado de São Paulo, a concentração máxima de sulfato permitida para efluentes líquidos lançados direta ou indiretamente nos corpos receptores é de $1,0 \mathrm{gSO}_{4}^{2-} \cdot t^{1}$. Neste caso, as Etapas I e II $\left(0,25\right.$ e $\left.0,50 \mathrm{gSO}_{4}^{-2} \cdot \mathrm{l}^{-1}\right)$ foram adotadas como sendo de imobilização e adaptação da biomassa inoculada no carvão mineral, já que, também, não foi encontrado lodo específico (sulfetogênico) para inoculação. Esperava-se que esse período de adaptação da biomassa fosse demorado, em virtude da necessidade de aclimatação da biomassa inoculada. No entanto, a colonização (imobilização) do meio suporte em presença do efluente industrial diluído em esgoto sanitário foi rápida, já que valores elevados de remoção de sulfato e de matéria orgânica foram obtidos desde o inicio de operação (Etapa I).

Foram obtidos resultados expressivos de redução de sulfato ao longo da operação do reator ASBBR. A eficiência média de redução de sulfato na Etapa I foi de 92\% (máx.: 99,8 \%) e na Etapa II de 88 \% (máx: 99,2\%), sendo que, no efluente do reator, nas respectivas Etapas, foram obtidos valores médios de sulfato de $0,021 \pm 0,01 \mathrm{gSO}_{4}^{-2} \cdot l^{-1}$ (min: $1 \mathrm{mgSO}^{-2} \cdot l^{-1}$ ) e de $0,064 \pm$ $0,02 \mathrm{gSO}_{4}^{-2} \cdot l^{-1}\left(\mathrm{~min}: 9 \mathrm{mgSO}_{4}^{-2} \cdot l^{-1}\right)$. Nas Etapas III, IV e $\mathrm{V}$ posteriores, atingiram-se, respectivamente, os valores de 89\% (máx.: 99,5\%), $87 \%$ (máx: 99,3\%) e $85 \%$ (máx: 99,1\%) em termos de eficiência média de remoção de sulfato. Os valores médios de sulfato no efluente foram $0,12 \pm 0,05 \mathrm{gSO}_{4}^{-2} \cdot t^{1}$ ( $\mathrm{min}$ : $\left.9 \mathrm{mgSO}^{-2} \cdot l^{1}\right), 0,26 \pm 0,07 \mathrm{gSO}^{-2} \cdot l^{-1}(\mathrm{~min}:$ $\left.9 \mathrm{mgSO}_{4}^{-2} \cdot t^{-1}\right)$ e de $0,48 \pm 0,18 \mathrm{gSO}_{4}^{-2} \cdot t^{-1}$ (min: $14 \mathrm{mgSO}_{4}^{-2} \cdot l^{-1}$ ) durante as correspondentes Etapas. 
Tabela 3 - Valores médios das variáveis aplicadas ao reator ASBBR (afluente) nas várias etapas de operação. COA = carga orgânica aplicada/ciclo; CAS = carga aplicada de sulfato/ciclo

\begin{tabular}{|c|c|c|c|c|c|}
\hline Variáveis & Etapa I & Etapa II & Etapa III & Etapa IV & Etapa V \\
\hline Número de ciclos & $7(5)$ & $24(16)$ & $21(14)$ & $9(6)$ & $31(20)$ \\
\hline CAS $\left(\mathrm{kgSO}_{4}^{-2} /\right.$ ciclo $)$ & $0,15 \pm 0,02$ & $0,30 \pm 0,03$ & $0,65 \pm 0,07$ & $1,30 \pm 0,14$ & $1,90 \pm 0,13$ \\
\hline $\mathrm{SO}_{4}^{-2}\left(\mathrm{~g} . \mathrm{l}^{-1}\right)$ & $0,25 \pm 0,03$ & $0,50 \pm 0,05$ & $1,08 \pm 0,12$ & $2,16 \pm 0,24$ & $3,12 \pm 0,23$ \\
\hline $\mathrm{DQO}^{*} /\left[\mathrm{SO}_{4}^{-2}\right]$ & $2,13 \pm 0,35$ & $1,89 \pm 0,65$ & $1,77 \pm 0,26$ & $1,64 \pm 0,40$ & $1,50 \pm 0,25$ \\
\hline COA (kgDQO/ciclo) & $0,60 \pm 0,05$ & $0,90 \pm 0,17$ & $1,40 \pm 0,16$ & $2,50 \pm 0,60$ & $3,0 \pm 0,47$ \\
\hline $\mathrm{DQO}_{\text {Total }}\left(\mathrm{g} \cdot \mathrm{l}^{-1}\right)$ & $0,98 \pm 0,08$ & $1,49 \pm 0,29$ & $2,35 \pm 0,27$ & $4,12 \pm 1,0$ & $5,08 \pm 0,78$ \\
\hline $\mathrm{DQO}_{\text {Filtrada }}\left(\mathrm{g} . \mathrm{l}^{-1}\right)$ & $0,54 \pm 0,08$ & $0,93 \pm 0,28$ & $1,89 \pm 0,26$ & $3,57 \pm 1,0$ & $4,63 \pm 0,78$ \\
\hline $\mathrm{AB}\left(\mathrm{mgCaCO}{ }_{3}^{-2} \cdot 1^{-1}\right)$ & $103 \pm 15$ & $103 \pm 45$ & $93 \pm 19$ & $84 \pm 13$ & $92 \pm 26$ \\
\hline AVT (mgHac. $\left.l^{-1}\right)$ & $67 \pm 11$ & $67 \pm 16$ & $112 \pm 23$ & $96 \pm 11$ & $119 \pm 33$ \\
\hline $\mathrm{pH}$ & 6,9 & 7,0 & 6,7 & 6,9 & 6,7 \\
\hline SST (mg.l-1) & $280 \pm 240$ & $177 \pm 83$ & $142 \pm 111$ & $115 \pm 39$ & $99 \pm 45$ \\
\hline SSV (mg.l-1) & $241 \pm 195$ & $141 \pm 70$ & $123 \pm 92$ & $90 \pm 14$ & $79 \pm 34$ \\
\hline $\mathrm{NH}_{4}^{+}\left(\mathrm{mg} \cdot \mathrm{l}^{-1}\right)$ & $77 \pm 5$ & $134 \pm 24$ & $236 \pm 67$ & $712 \pm 68$ & $715 \pm 82$ \\
\hline
\end{tabular}

( ) número de amostras e ${ }^{\mathrm{DQO}}$ Filtrada

Tabela 4 - Resultados médios das variáveis obtidas pelo reator ASBBR (efluente) nas várias etapas de operação. $\mathrm{COR}=$ carga orgânica removida/ciclo; CRS = carga removida de sulfato/ciclo

\begin{tabular}{|c|c|c|c|c|c|}
\hline Variáveis & Etapa I & Etapa II & Etapa III & Etapa IV & Etapa V \\
\hline Número de ciclos & $7(5)$ & $24(16)$ & $21(14)$ & $9(6)$ & $31(20)$ \\
\hline *Temperatura $\left({ }^{\circ} \mathrm{C}\right)$ & $24 \pm 3$ & $31 \pm 3$ & $30 \pm 3$ & $35 \pm 1$ & $34 \pm 1$ \\
\hline CRS ( $\mathrm{kg} \mathrm{SO}_{4}^{-2} /$ ciclo) & $0,15 \pm 0,01$ & $0,25 \pm 0,04$ & $0,60 \pm 0,07$ & $1,15 \pm 0,12$ & $1,60 \pm 0,21$ \\
\hline $\mathrm{SO}_{4}^{-2}\left(\mathrm{~g} \cdot \mathrm{l}^{-1}\right)$ & $0,021 \pm 0,01$ & $0,064 \pm 0,02$ & $0,12 \pm 0,05$ & $0,26 \pm 0,07$ & $0,48 \pm 0,18$ \\
\hline **STD (mg. $\left.1^{-1}\right)$ & $4,0 \pm 0,9$ & $25 \pm 8$ & $132 \pm 32$ & $221 \pm 71$ & $287 \pm 132$ \\
\hline COR (kgDQO/ciclo) & $0,52 \pm 0.03$ & $0,70 \pm 0.11$ & $0,95 \pm 0.12$ & $1,75 \pm 0.32$ & $1,20 \pm 0.46$ \\
\hline $\mathrm{DQO}_{\text {Total }}\left(\mathrm{g} \cdot \mathrm{l}^{-1}\right)$ & $0,14 \pm 0,03$ & $0,33 \pm 0,08$ & $0,72 \pm 0,16$ & $1,45 \pm 0,35$ & $3,01 \pm 0,57$ \\
\hline $\mathrm{DQO}_{\text {Filtrada }}\left(\mathrm{g} . \mathrm{l}^{-1}\right)$ & $0,11 \pm 0,03$ & $0,24 \pm 0,07$ & $0,57 \pm 0,15$ & $1,07 \pm 0,33$ & $2,77 \pm 0,56$ \\
\hline $\mathrm{AB}\left(\mathrm{mgCaCO}{ }^{-2} \cdot 1^{-1}\right)$ & $301 \pm 48$ & $471 \pm 50$ & $790 \pm 171$ & $1533 \pm 197$ & $765 \pm 772$ \\
\hline AVT (mgHac. $\left.l^{-1}\right)$ & $24 \pm 20$ & $49 \pm 45$ & $172 \pm 63$ & $238 \pm 204$ & $1552 \pm 641$ \\
\hline $\mathrm{pH}$ & 7,1 & 7,3 & 7,1 & 7,3 & 6,7 \\
\hline SST (mg. $\left.1^{-1}\right)$ & $35 \pm 24$ & $32 \pm 17$ & $46 \pm 32$ & $37 \pm 15$ & $40 \pm 12$ \\
\hline SSV (mg..$\left.^{-1}\right)$ & $25 \pm 20$ & $23 \pm 12$ & $38 \pm 33$ & $32 \pm 14$ & $27 \pm 12$ \\
\hline $\mathrm{NH}_{4}^{+}\left(\mathrm{mg} . l^{-1}\right)$ & $67 \pm 17$ & $133 \pm 16$ & $327 \pm 65$ & $645 \pm 54$ & $721 \pm 86$ \\
\hline
\end{tabular}

( ) número de amostras, *líquido $\mathrm{e}^{* *}$ sulfetos totais dissolvidos

As cargas médias aplicadas (CAS) e removidas de sulfato (CRS) por ciclo para as Etapas I, II, III, IV e V estão apresentadas na Figura 2. A carga inicial aplicada foi de $0,15 \mathrm{kgSO}_{4}^{2-}$ / ciclo, tendo-se atingido $1,9 \mathrm{kgSO}_{4}^{2-} /$ ciclo, enquanto a carga removida máxima foi de 1,6 $\mathrm{kgSO}_{4}{ }^{2-} /$ ciclo (Etapa V).

As cargas orgânicas aplicadas variaram de 0,6 a 3,0 kgDQO/ciclo nas várias Etapas e as médias de eficiências de remoção de DQO foram superiores a $80 \%$ nas Etapas I e II, decrescendo para médias de $41 \%$ na Etapa V. A baixa eficiência de remoção de matéria orgânica detectada nesse período específico deveu-se à presença de alta concentração de DQO residual, composta, principalmente, de ácidos voláteis totais (AVT) e de sulfetos totais dissolvidos (STD) gerados pela redução do sulfato (Tabela 4), além de uma fração de sólidos voláteis que é carreado juntamente com o efluente. No que se refere à matéria orgânica solúvel, a presença de ácidos orgânicos no efluente indica que o processo metanogênico foi inibido, uma vez que este é o principal processo de consumo de ácidos orgânicos em reatores anaeróbios. Ressalta-se que a carga aplicada em termos de DQO foi gerada, principalmente, a partir da Etapa II, pela adição de etanol como doador de elétrons para o processo de redução do sulfato. $\mathrm{Na}$ Figura 3, são apresentadas, as cargas 
médias orgânicas aplicadas (COA) e removidas (COR) por ciclo, em termos de DQO, para as Etapas I, II, III, IV e V.

No efluente do ASBBR, atingiramse as médias para $\mathrm{DQO}_{\mathrm{Bruta}_{\mathrm{a}}}$ e $\mathrm{DQO}_{\mathrm{E}}$ de $0,14 \pm 0,03$ g. $l^{1}$ e de $0,11 \pm 0,03 \mathrm{~g} . l^{1}$

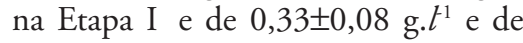
$0,24 \pm 0,07$ g. $l^{-1}$ na Etapa II, enquanto que, nas Etapas III, IV e $\mathrm{V}$ estes valores foram de $0,72 \pm 0,16$ g. $l^{1}$ e $0,57 \pm 0,15$ g. $l^{1}$, $1,45 \pm 0,35$ g. $l^{-1}$ e $1,07 \pm 0,33$ g. $t^{1}$ e de $3,01 \pm 0,57$ g. $t^{1}$ e $2,77 \pm 0,56$ g. $t^{1}$, respectivamente.

Especificamente na Etapa V, as concentraçôes médias de sulfeto total dissolvido (STD) foram de $287 \pm 132 \mathrm{mg} . t^{1}$ (máx: $496 \mathrm{mg} . t^{1}$ ), sendo que a média do $\mathrm{pH}$ no efluente decresceu de 7,3 (Etapa IV) para 6,7 (Etapa V), o que indica maior concentração da forma $\mathrm{H}_{2} \mathrm{~S}$ no meio líquido. $\mathrm{O}$ pH foi influenciado pelo aumento da concentração de ácidos voláteis totais (AVT) produzidos pela oxidação parcial do etanol pelos microrganismos redutores de sulfato (MRS) para ácidos voláteis, principalmente o ácido acético. A presença de sulfeto na forma de $\mathrm{H}_{2} \mathrm{~S}$, em alta concentração, pode ser considerado o fator mais importante que levou à inibição da atividade metanogênica no reator na presente pesquisa.

Muitos dos estudos referentes à toxicidade do sulfeto tiveram como foco principal a inibição da metanogênese. Presume-se que o efeito inibitório do sulfeto seja devido à forma não dissociada $\left(\mathrm{H}_{2} \mathrm{~S}\right)$, porque somente moléculas podem permear a membrana celular (Lens et al,1998). Atravessando a parede celular, a molécula de $\mathrm{H}_{2} \mathrm{~S}$ pode desnaturar proteínas ou importantes enzimas metabólicas por meio da formação de sulfeto e dissulfeto entre as cadeias polipeptídicas. O efeito inibitório do $\mathrm{H}_{2} \mathrm{~S}$ sobre os MRS tem sido também abordado na literatura sob controvérsias (O'Flaherty \& Colleran, 2000). Isa et al (1986) relataram que altos níveis de sulfeto de hidrogênio (até $1000 \mathrm{mg} . \iota^{-1}$ ) não afetaram o crescimento de MRS em reator anaeróbio de alta taxa em escala de bancada. Porém, a literatura apresenta valores discordantes para as concentrações de $\mathrm{H}_{2} \mathrm{~S}$ que provocam a inibição dos processos metanogênicos e sulfetogênicos em reatores submetidos a concentrações elevadas de sulfato. $\mathrm{Na}$ presente pesquisa, a inibição da sulfetogênese não foi detectada na faixa de concentrações de sulfato aplicada ao reator ASBBR.

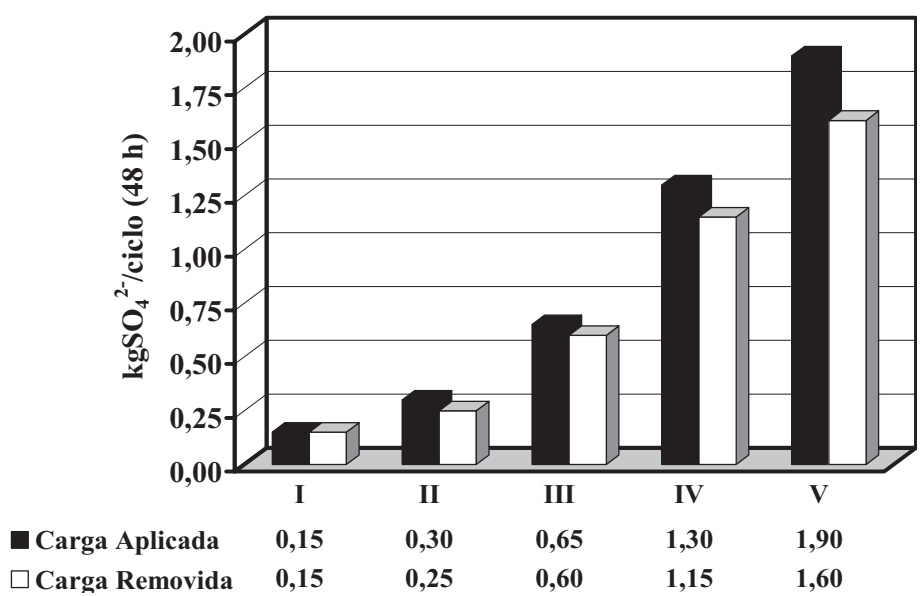

Figura 2 - Cargas médias de sulfato aplicadas e removidas nas várias Etapas (I, II, III, IV e V) de operação do reator ASBBR

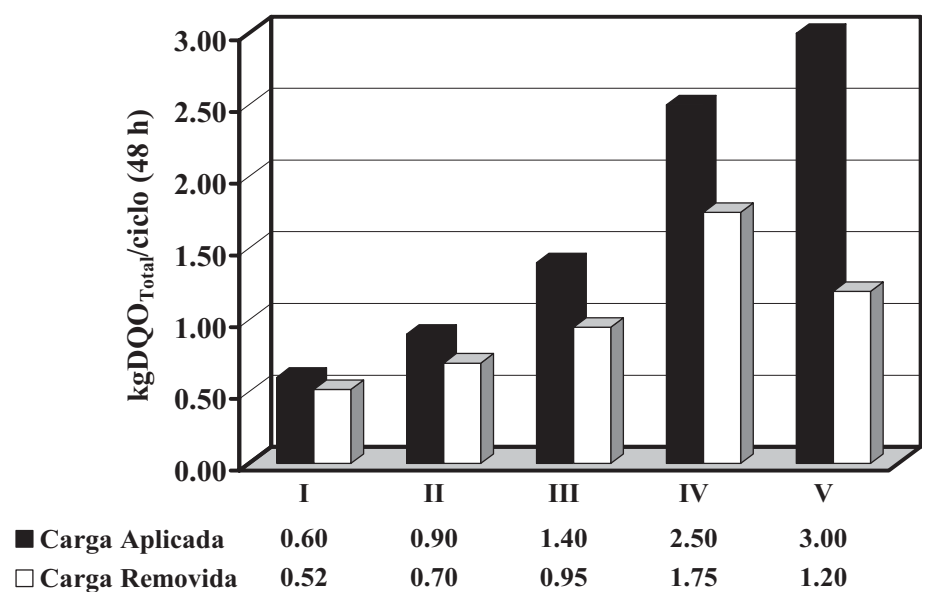

Figura 3 - Cargas orgânicas médias aplicadas e removidas nas várias Etapas (I, II, III, IV e V) de operação do reator ASBBR

A Figura 4 mostra as variaçoes das concentrações médias de ácidos voláteis totais (AVT) e alcalinidade a bicarbonato $\mathrm{AB}$ no efluente, ao longo da operação do ASBBR. O valor e a estabilidade do $\mathrm{pH}$, nos reatores anaeróbios, são governados pelo sistema carbonato-gás carbônico. A AB presente no esgoto sanitário, juntamente com a produzida no reator garantiu a capacidade de tamponamento, devido à remoção de ácidos voláteis e ao processo de amonificação.

Somente na Etapa V foi observada a queda de $\mathrm{pH}$ (médio) para o valor de 6,7 (Tabela 4). Nessa Etapa, houve o aumento exagerado na concentração de AVT presente no efluente (Figura 4) e, conseqüentemente, o consumo proporcional de $\mathrm{AB}\left(765 \pm 772 \mathrm{mgCaCO} . .^{1}\right)$. Portanto, a presença de DQO resi- dual no efluente é explicada pela alta concentração de AVT presente $\left(1552 \pm 641 \mathrm{mgHac} \mathrm{l}^{-1}\right)$ e fortalece a hipótese de supressão da metanogênese nesse período na presença de altas concentraçōes de sulfetos. Portanto, o etanol oxidado parcialmente pelos MRS, foi convertido a acetato, o qual foi pouco consumido pelos organismos metanogênicos.

A geração de alcalinidade nos reatores foi crescente para as quatro primeiras Etapas, com valores médios de $\mathrm{AB}$ no efluente de $301 \pm 48 \mathrm{mgCaCO}_{3} \cdot l^{-1}$ (Etapa I), $471 \pm 50 \mathrm{mgCaCO}_{3} \cdot l^{-1}$ (Etapa II), 790 \pm 171 (Etapa III) e $1533 \pm 197 \mathrm{mgCaCO} \cdot l^{-1}$ (Etapa IV). A produção de alcalinidade observada pode ser explicada pelo consumo de AVT até na Etapa IV. No efluen- 
te, foram obtidos valores médios de AVT nas Etapas I, II, III e IV de $24 \pm 20 \mathrm{mgHac} . l^{-1}, 49 \pm 45 \mathrm{mgHac} . l^{-1}$, $172 \pm 63$ mgHac. $t^{1}$ e $238 \pm 204 \mathrm{mgHac} . l^{1}$, respectivamente.

A Figura 5 permite observar o aumento da concentração de biomassa em termos de sólidos totais voláteis (STV) no carvão mineral nas Etapas I e II, decorrente do processo de adaptação da biomassa. Na Etapa I, a concentração foi de $0,06 \mathrm{kgSTV} / \mathrm{kg}$ carvão e na Etapa II de $0,18 \mathrm{kgSTV} / \mathrm{kg}$ carvão. Nas Etapas subseqüentes, os valores foram semelhantes e, ao final da Etapa V, alcançouse o valor de $0,19 \mathrm{kgSTV} / \mathrm{kg}$ carvão. Para a massa de carvão mineral de $500 \mathrm{~kg}$ utilizada para a formação do leito do reator, tem-se, na Etapa V, o valor de $95 \mathrm{kgSTV}$, como medida indireta total da biomassa imobilizada no meio suporte do ASBBR. O aumento progressivo da concentração de biomassa presente no carvão mineral confirma a afirmativa anterior quanto à rápida colonização (imobilização) do meio suporte nas Etapas I e II.

Em relação à remoção de sólidos suspensos totais e voláteis, as médias mantiveram-se superiores a $80 \%$ nas Etapas I e II. Os resultados obtidos no efluente foram de $35 \pm 24 \mathrm{mgSST} . \mathrm{t}^{-1} \mathrm{e}$ de $25 \pm 20 \mathrm{mgSSV} . l^{-1}$ (Etapa I) e de $32 \pm 17$ mgSST. $t^{1}$ e de $23 \pm 12 \mathrm{mgSSV} . t^{1}$ (Etapa II). A elevada remoção de sólidos suspensos nas Etapas I e II está relacionada com o processo de imobilização e adaptação da biomassa inoculada no carvão mineral. Já nas Etapas posteriores, as médias de remoção de sólidos suspensos diminuíram para a faixa entre 60 e $70 \%$. As concentrações médias de sólidos suspensos no efluente foram de $46 \pm 32 \mathrm{mgSST} . \mathrm{l}^{-1}$ e $38 \pm 33 \mathrm{mgSSV}^{-1}$ na Etapa III; $37 \pm 15 \mathrm{mgSST} . \mathrm{l}^{-1}$ e $32 \pm 14 \mathrm{mgSSV} . \mathrm{l}^{-1}$ na Etapa IV; e $40 \pm 12 \mathrm{mgSST} . l^{-1} \mathrm{e}$ $27 \pm 12 \mathrm{mgSSV} . \mathrm{l}^{-1}$ na Etapa V. Os baixos valores, principalmente, em termos de sólidos suspensos voláteis (SSV) no efluente indicaram perda reduzida de biomassa do reator após cada ciclo.

$\mathrm{Na}$ Tabela 3, nota-se que, na Etapa I, o valor médio da relação $\mathrm{DQO} /\left[\mathrm{SO}_{4}{ }^{2-}\right]$ foi de 2,13 pela presença apenas de esgoto sanitário. Nas Etapas II, III, IV e V II, com a introdução de etanol, adequou-se a relação $\mathrm{DQO} /\left[\mathrm{SO}_{4}{ }^{2-}\right]$, a fim de alcançar as maiores eficiências de redução de sulfato. Os valores médios da relação $\mathrm{DQO} /\left[\mathrm{SO}_{4}^{2-}\right]$ reduziram-se gradual-

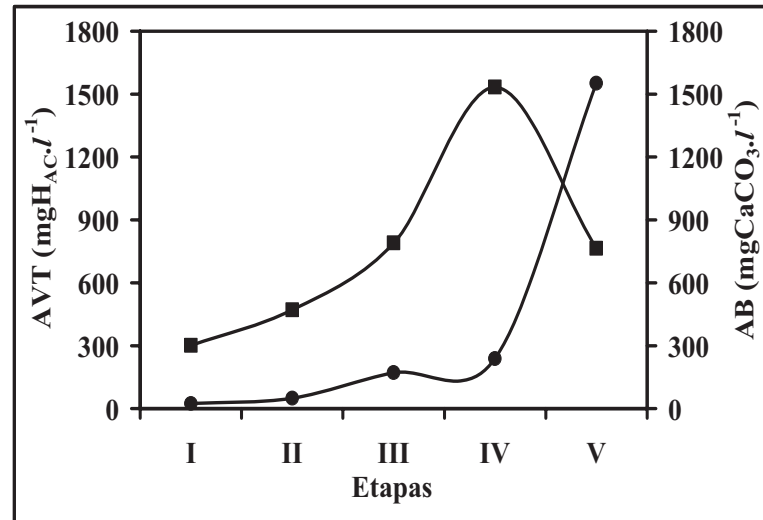

Figura 4 - Valores médios da concentração de AVT (•) e $A B$ ( $\square$ ) no efluente do ASBBR nas várias etapas de operação

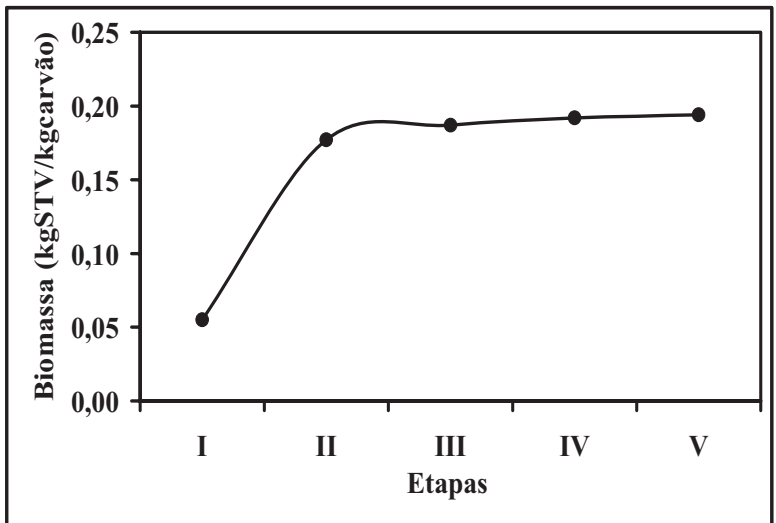

Figura 5 - Variação da concentração de biomassa presente no carvão mineral nas várias etapas de operação do ASBBR

mente com o aumento da concentração de sulfato para 1,89 (Etapa II), 1,77 (Etapa III), 1,64 (Etapa IV) e 1,50 (Etapa V). Tais resultados indicam que houve diminuição no consumo de etanol em função da carga removida (CRS) nas várias etapas de operação do ASBBR. Os valores obtidos de consumo de etanol (médio) foram de 1,62, 1,35; 1,27 e $1,06 \mathrm{~kg}$ etanol/ $\mathrm{kg} \mathrm{SO}{ }_{4}^{2-/}$ ciclo (removido).Considerou-se densidade do etanol combustível de $810 \mathrm{~kg} \cdot \mathrm{m}^{-3}$.

O consumo de etanol é de grande importância no processo de redução de sulfato, já que a sua aplicação envolve o custo do produto. Como o etanol utilizado é o mesmo vendido em postos, o preço por litro está em torno de R\$ 1,30 (\$USD 0.60/litro). Na Etapa I, o esgoto sanitário foi adicionado como matéria orgânica, portanto, a custo zero. Para a Etapa V, ao remover-se a carga de $1,6 \mathrm{kgSO}^{2-/}$ ciclo, o custo calculado foi de R\$2,52 por ciclo (US\$ 1.17), ou seja, $\mathrm{R} \$ 1,57 / \mathrm{kgSO}_{4}{ }_{4}^{2-}$ (removido). $\mathrm{O}$ valor é baixo, mas não foram encon- trados dados na Literatura como forma de comparação.

$\mathrm{O}$ efluente industrial utilizado para tratamento do ASBBR tem como base sulfato de amônio gerado pelo uso de $\mathrm{H}_{2} \mathrm{SO}_{4}$ e amônia líquida no processo de sulfonação e matéria orgânica residual proveniente do óleo vegetal empregado no processo. Paralelamente, a forma de nitrogênio amoniacal foi monitorada semanalmente ( 2 coletas). Esse monitoramento teve como objetivo avaliar a ocorrência de interações entre os ciclos do nitrogênio e do enxofre, conforme apontado por alguns autores (Fernandez-Polanco et al, 2001; Lens \& Hulshoff-Pol, 1998). Segundo estes autores, até o momento, as interações comumente detectadas entre estes ciclos em ecossistemas microbianos estão de acordo com relatos de tratamentos anaeróbios convencionais de efluentes com altas concentrações de matéria orgânica, nitrogênio e sulfatos.

Pelos resultados obtidos, não se notou a citada remoção simultânea 
de sulfato e nitrogênio (Tabela 4). As concentraçóes médias de nitrogênio amoniacal foram muito próximas tanto na Etapa I (afluente: $77 \pm 5 \mathrm{mgNH}_{4}^{+} . l^{-1} \mathrm{e}$ efluente: $\left.67 \pm 17 \mathrm{mgNH}_{4}^{+} . l^{-1}\right)$, como na Etapa II (afluente: $134 \pm 24 \mathrm{mgNH}_{4}^{+} . t^{-1}$ e efluente: $\left.133 \pm 16 \mathrm{mgNH}_{4}^{+} . l^{1}\right)$. Com o aumento contínuo da concentração de sulfato no ASBBR e conseqüente elevação das concentrações de matéria orgânica (DQO) e de nitrogênio, esperavase a possível interação entre os ciclos do enxofre e do nitrogênio, o que não ocorreu. Na Etapa III, os resultados médios de nitrogênio amoniacal no afluente e efluente foram de $236 \pm 67 \mathrm{mgNH}_{4}^{+} . l^{1}$ e $327 \pm 65 \mathrm{mgNH}_{4}^{+} . l^{1}$, na Etapa IVde $712 \pm 68 \mathrm{mgNH}_{4}^{+} . l^{-1} \mathrm{e}$ $645 \pm 54 \mathrm{mgNH}^{+} . l^{-1}$ e na Etapa $\mathrm{V}$ de $715 \pm 82 \mathrm{mgNH}_{4}^{+} . l^{1}$ e $721 \pm 86 \mathrm{mgNH}_{4}^{+} . l^{1}$, respectivamente.

\section{CONCLUSÕES}

A aplicação de tratamento biológico em efluente industrial contendo elevadas concentrações de sulfato forneceu resultados expressivos em termos de redução de sulfato (88 a 92\%), o que permite vislumbrar a possibilidade de uso de reator anaeróbio ASBBR para tal finalidade e, no futuro, a aplicação em larga escala no tratamento de outras águas residuárias ricas em sulfato.

Os resultados de desempenho do ASBBR demonstram o grande potencial desta configuração de reator, não, somente para a remoção de sulfato, mas para a remoção conjunta de matéria orgânica e sulfato em faixas apreciáveis para valores de até $2,0 \mathrm{gSO}_{4}^{2-} \cdot t^{-1}$ (Etapa IV). Tais valores permitiram a adequação do efluente do ASBBR ao padrão de emissão deste íon no Estado de São Paulo $\left(<\cdot 1,0 \mathrm{gSO}_{4}^{2-} \cdot l^{-1}\right)$.

Constatou-se, no entanto, a formação de altas concentraçôes de compostos reduzidos de enxofre (STD) e de DQO residual para concentrações de sulfato superiores a $2,0 \mathrm{gSO}_{4}^{2-} \cdot l^{-1}$. Por essa razão, a aplicação desse processo em escala industrial torna necessária a implantação de sistema de tratamento complementar para adequar os efluentes aos padrões de emissão. A remoção da DQO residual composta essencialmente por ácidos orgânicos (por exemplo, o acético) é relativamente simples podendo ser utilizados reatores biológicos aeróbios ou anaeróbios.

A remoção de compostos reduzidos de enxofre dos efluentes líquidos e gasosos deve ser concebida de maneira a tornar possível a produção de enxofre elementar, de maneira a direcionar os sistemas de tratamento para recuperação de subprodutos e assim torná-los mais sustentáveis do ponto de vista ambiental e econômico. $\mathrm{Na}$ forma de enxofre elementar existe a viabilidade de retorno a cadeia produtiva (ácido sulfúrico), bem como de condicionante de solo.

Esta pesquisa teve como foco principal, apontar uma solução possível para a remoção biológica do sulfato utilizando tecnologia e materiais disponíveis no país. Novos estudos estão sendo desenvolvidos focados diretamente no pós-tratamento, bem como na recuperação do enxofre elementar.

\section{AGRADECIMENTOS}

A Fundação de Amparo à Pesquisa do Estado de São Paulo (FAPESP-Processo no 03/07799-2) e ao Conselho Nacional de Desenvolvimento Científico e Tecnológico (Edital Universal $\mathrm{n}^{0}$ 019/2004 - Processo no 478355/2004-1) pelo apoio financeiro na execução da pesquisa.

\section{REFÊRENCIAS}

APHA, AWWA, WPCF. Standard Methods for the examination of water and wastewater, $20^{\text {th }}$ edition, American Public Health Association, Washington, 1998.

CHIAN, E.S.K and DE WALLE, F.B. Removal of heavy metals from a fatty acid wastewater with a complete mixed anaerobic filter. Proceedings $38^{\text {th }}$ Industrial Waste Conference, Purdue University, West Lafayette, IN, pp. 920-927, 1983.

DE SMUL, A. et al. High rates of microbial sulfate reduction in a mesophilic ethanol-fed expandedgranular-sludge-blanket reactor. Applied Microbiology Biotechnology, 48, p.297-303, 1997.

DILALLO, R. and ALBERTSON, O.E. Volatile acids by direct tritation. Journal WPCF, v.33, p.356-365, 1961.

DU PREEZ, L.A. and MAREE, J.P. Pilot-scale biological sulphate and nitrate removal utilizing producer gas as energy source. Water Science \& Technology, 30 (12), pp. 275-285,1994.

FDZ-POLANCO, F. et al. Simultaneous organic nitrogen and sulfate removal in an anaerobic gac fluidized bed reactor. Water Science \& Tecnology, vol. 44, pp. 15-22, 2001.

FEDEROVICH, V.et al. Use of hydrophobic membranes to supply hydrogen to sulphate reducing bioreactor. Biodegradation, 11, pp. 295-303, 2000.

GROBICKI, A. and STUCKEY, D.C. Hydrodinamic characteristics of the anaerobic baffled reactor. Water Research, 23 (3), pp.371-378, 1992.
HERRERA, L.J. et al. Desulfovibrio desulfuricans growth kinetics. Environmental Toxicology Water Quality, 6, pp. 225-238, 1991.

HULSHOFF-POL, L.W. et al. New developments in reactor and process technology for sulfate reduction. Water Science and Technology, 44 (8), pp. 67-76, 2001.

KAUFMAN, E.N., LITTLE, M.H., SELVARAJ, P.T. A biological process for the reclamation of flue gas desulfurization using mixed sulfate reducing bacteria with inexpressive carbon sources. Applied Biochemistry Biotechnology, 63-65, p.677-693, 1996.

LENS, P.N.L., HULSHOFF POL, L.W. Biological sulfur cycle: Environmental Science and Tecnology (special issue Biodegradation, 9, n.3-4), 1998.

LENS, P.N.L. et al. Biotechnological treatment of sulfate-rich wastewaters. Critical Reviews in Environmental Science and Technology, 28 (1), p. 41-88, 1998.

NAGPAL, S.et al. Microbial sulfate reduction in a liquid-solid fluidized bed reactor. Biotechnology Bioengineering, 70(4), pp.370-379, 2000.

O'FLAHERTY, V. and COLLERAN, E. Sulfur problems in anaerobic digestion. In: LENS, P.N.L., HULSHOFF POL, L.W. (eds). Environmental technologies to treat sulfur pollution: principles and engineering. IWA publishing, London, UK, 467-489, 2000).

RIPLEY, L.E., BOYLE, W.C., CONVERSE, J.C. Improved alkalimetric monitoring for anaerobic digestion of high-strength wastes. Journal WPCF, v.58, p. 406-411, 1986.

SILVA, A.J.et al. Evaluation of support materials for the immobilization of sulfate-reducing bacteria and methanogenic archaea. Anaerobe, 12, p. 93-98, 2006.

SILVA, A.J.et al. Sulphate removal from industrial wastewater using a packed-bed anaerobic reactor. Process Biochemistry, 37, p. 927-935, 2002.

STUCKI, G., HANSEMANN, K.W., HÜRZELER, A. Biological sulfuric acid transformation: reactor design and process optimization. Biotechnology Bioengineering, 41, pp.303-315, 1993.

VAN HOUTEN, R.T.et al. Biological sulphate reduction using synthesis gas as energy and carbon source. Biotechnology Bioengineering, 50, pp.136-144, 1995.

WEIJMA J. et al. Optimization of sulphate reduction in a methanol-fed thermophilic bioreactor. Water Research, 36, pp.1825-1833, 2002.

Endereço para correspondência:
Arnaldo Sarti
Departamento de Hidráulica e
Saneamento
EESC/USP
Av.Trabalhador Sãocarlense, 400
I3566-590 São Carlos - SP - Brasil
Tel.: (I6) 3373-9560
Fax:(I6) 3373-9550
E-mail: arnaldosarti@gmail.com 